\title{
Effect of Foliar Trimming and Fungicides on Apothecial Number of Sclerotinia sclerotiorum, Leaf Blight Severity, Yield, and Canopy Microclimate in Carrot
}

\author{
Mary Ruth McDonald, Kevin D. Vander Kooi, and Sean M. Westerveld, Department of Plant Agriculture, Uni- \\ versity of Guelph, Guelph, Ontario N1G 2W1, Canada
}

\begin{abstract}
McDonald, M. R., Vander Kooi, K. D., and Westerveld, S. M. 2008. Effect of foliar trimming and fungicides on apothecial number of Sclerotinia sclerotiorum, leaf blight severity, yield, and canopy microclimate in carrot. Plant Dis. 92:132-136.

Foliar trimming of the carrot canopy has potential for reducing the severity of Sclerotinia (Sclerotinia sclerotiorum) rot of carrot (Daucus carota subsp. sativus). The effect of trimming the carrot foliage once or twice, with and without fungicide application, was examined on carrot plants grown on organic soil for 3 years at the University of Guelph-Muck Crops Research Station in Ontario, Canada. The number of S. sclerotiorum apothecia, carrot leaf blight (CLB; Alternaria dauci and Cercospora carotae) severity, canopy microclimate, and total and marketable yield were assessed. The number of apothecia of S. sclerotiorum and relative humidity in the canopy were reduced by trimming done at either the first observation of apothecia or at 100 days after seeding (DAS). In both cases, the effects of trimming on canopy microclimate lasted between 2 and 4 weeks. Trimming the canopy twice during the season did not reduce the number of apothecia compared with trimming the canopy once at 100 DAS. Foliar trimming had little effect on CLB severity. This was attributed mainly to the lower requirement of the CLB pathogens for prolonged periods of high relative humidity and leaf wetness compared with S. sclerotiorum. Foliar trimming did not improve the efficacy of fungicide applications for CLB control. Trimming the canopy once or twice had no effect on total or marketable yield. Thus, trimming has potential to improve the management of Sclerotinia rot of carrot, and trimming both at first observation of apothecia and at 100 DAS could reduce apothecia production and relative humidity within the canopy.
\end{abstract}

Sclerotinia ( $S$. sclerotiorum (Lib.) de Bary) rot of carrot is a destructive field and storage disease of carrot (Daucus carota $\mathrm{L}$. subsp. sativus (Hoffm.) Arcang.) in Ontario and worldwide (14). Losses in storage can exceed $30 \%$ (8). Severe Sclerotinia rot in the field can weaken carrot foliage, causing it to break off during mechanical harvest, leaving carrot roots in the ground unharvested. The development of Sclerotinia rot in storage is dependent on infection occurring in the field during the growing season (7). However, once roots are infected, the severity of storage losses often is determined by storage conditions.

Infection of carrot by $S$. sclerotiorum in the field occurs primarily through ascospore germination and direct penetration of senescing leaves $(10,13,14)$. Infection is dependent on long periods of leaf wetness provided by high humidity and high soil moisture, and the optimal temperatures are between 15 and $18^{\circ} \mathrm{C}$ (23). Once the pathogen infects the leaves, mycelium can progress down the petioles of senescing

Corresponding author: S. M. Westerveld

E-mail: swesterv@uoguelph.ca

Accepted for publication 4 August 2007.

doi:10.1094/PDIS-92-1-0132

(C) 2008 The American Phytopathological Society leaves and into the crown, where storage rots are initiated $(9,7,10,13,15)$. Optimal conditions for $S$. sclerotiorum infection occur after full canopy closure later in the growing season $(2,4,16)$. Thus, control of the disease is targeted to this stage of growth. There are no fungicides currently registered for controlling Sclerotinia rot on carrot in Ontario; however, fungicides are applied regularly to control carrot leaf blight (CLB) and might have some effect in protecting foliage from $S$. sclerotiorum infection.

Researchers in Ontario have investigated foliar trimming, a technique developed in Washington State, as a method to delay canopy closure, improve airflow through the canopy, and reduce infection by $S$. sclerotiorum (16). Trimming the canopy once, upon first observation of apothecia, reduces the number of apothecia produced. Foliar trimming results in increased maximum air and soil temperatures compared with untrimmed plots and decreased humidity in the furrow, resulting in an environment that is unsuitable for infection and disease development (16). It also is possible that foliar trimming could improve fungicide penetration into the canopy and improve control of CLB on the leaves and petioles.

With a single foliar trimming, the carrot canopy can close prior to and after trimming. If apothecia developed in early Au- gust and the canopy was trimmed at that time, reclosure can occur by the end of August, resulting in a 1- to 2-month period in which conditions once again are conducive to disease development. Consequently, an additional foliar trimming treatment during the season could delay the canopy closure and further reduce disease development. The effects of secondary foliar trimming or different timings of trimming have not been examined.

Alternaria (Alternaria dauci (J.G. Kühn) J.W. Groves \& Skolko) and Cercospora (Cercospora carotae (Pass.) Solheim) leaf blights of carrot are among the most common and destructive diseases of carrot worldwide $(3,21,22)$. The diseases typically are managed as one disease, CLB, in Ontario. In contrast to Sclerotinia rot, which is sporadic, CLB is destructive in most years. Both leaf blights are favored by long periods of leaf wetness, usually associated with high humidity. Infection by A. dauci on carrot leaves occurs after 12 to $16 \mathrm{~h}$ of continuous leaf wetness $(12,17)$. $C$. carotae requires leaf wetness for $24 \mathrm{~h}$ or more for infection (5), but consecutive periods of leaf wetness interrupted with dry periods of $\leq 12 \mathrm{~h}$ can be considered as a single wetness period, because the pathogen can survive extended dry periods (6). In Ontario, leaf wetness periods greater than $12 \mathrm{~h}$ and, consequently, infection periods, occur most days in August and September, especially in fields where the canopy has closed. Thus, foliar trimming of carrot plants and the subsequent reduction in humidity and leaf wetness may reduce the severity of CLB in the absence of fungicides. Foliar trimming also could improve the penetration of fungicides into the canopy and further improve control of CLB. Even with disease forecasting, growers apply 5 to 10 fungicide sprays per season (24). Consequently, any improvement in the effectiveness of fungicide application for control of CLB could result in a significant decrease in grower costs. The removal of older, senescing leaves in the foliar trimming process also could result in reduced Alternaria leaf blight severity, because A. dauci infects predominately older and senescing leaves (19).

The objectives of this study were to determine (i) if trimming twice during the season could reduce the number of apothecia of S. sclerotiorum and severity of Sclerotinia rot in storage compared with a sin- 
gle trim, and if timing of these trimmings could be improved; (ii) the effect of foliar trimming on the severity of CLB; and (iii) if foliar trimming in combination with fungicide sprays could improve fungicide efficacy and further reduce CLB.

\section{MATERIALS AND METHODS}

Experiments were conducted on organic soil, a typic humisol-muck ( $\mathrm{pH} 6.4$, organic matter $60 \%$ ), naturally infested with $S$. sclerotiorum at the University of Guelph-Muck Crops Research Station, Holland/Bradford Marsh, Ontario, Canada $\left(44^{\circ} 5^{\prime} \mathrm{N}, 79^{\circ} 35^{\prime} \mathrm{W}\right)$. There were $68.8 \pm$ 24.3 sclerotia of $S$. sclerotiorum per square meter in the top $0.5 \mathrm{~cm}$ of soil within $25 \mathrm{~m}$ of these research plots (13). Carrot cv. Cellobunch was direct seeded with a precision seeder ( 80 to 90 seeds $/ \mathrm{m}$ ) on 3 June 2002, 21 May 2003, and 18 May 2004 on raised beds $20 \mathrm{~cm}$ high and $86 \mathrm{~cm}$ apart. A randomized complete block design with four replications per treatment was used. Each experimental unit consisted of four 5$\mathrm{m}$-long rows of carrot plants in 2002 and 2003 and four 10-m-long rows in 2004. The trials were conducted at a different location on the Muck Crops Research Station each year. Fertilizers were applied according to provincial recommendations (20).

The trial was a factorial design with two factors. One factor was trimming with three levels: (i) untrimmed, (ii) trimmed 100 days after seeding (DAS), and (iii) trimmed twice, at first observation of apothecia and once the canopy reclosed. The second factor was fungicide application at two levels: (i) untreated and (ii) the fungicide Lance (70\% boscalid; BASF Canada Inc., Mississauga, ON, Canada) was applied at $0.32 \mathrm{~kg} / \mathrm{ha}$. Fungicide was applied using a tractor-drawn, pull-type plot sprayer with TeeJet D-2 hollow cone nozzles at $690 \mathrm{kPa}$ (boom) in water at 500 liters/ha. Application techniques were designed to match commercial fungicide application practices. Five to six fungicide applications were applied each year on 23 August, 9, 19, and 23 September, and 4 and 10 October 2002; 20 and 28 August, 11, 17, and 26 September, and 7 October 2003; and 5 and 20 August, 13 and 30 September, and 10 October 2004. The vertical trimming of the carrot canopy was performed using a gas-operated hand-held hedge trimmer (Stihl, Model HS45, 27-cc engine with a $60-\mathrm{cm}$ double-edge cutting blade). The trimmer was held vertically, touching the base of the bed, and was moved along the carrot row to cut off overlapping leaves above the furrow and lodged senescing leaves on both sides of the row. The trimmed plant debris remained in the furrow. Carrot plants were trimmed either once, 100 DAS on 11 September 2002, 29 August 2003, and 27 August 2004, or twice, upon first observation of apothecia and once the canopy reclosed on 20 August and 18 September 2002, 7 August and 29 August 2003, and 29 July and 17 September 2004.

One furrow in each treatment (2002 and 2003) and $5 \mathrm{~m}$ of each furrow (2004) were evaluated weekly for the number of apothecia of S. sclerotiorum. Leaf blight was assessed on 24 September and 1 October 2002; 26 August, 9 and 16 September, and 7 October 2003; and 31 August, 21 September, and 27 October 2004. The entire canopy within the middle rows of each experimental unit was rated for CLB severity on a scale from 0 to 5 , where $0=$ no leaf area diseased, $1=<25 \%$ diseased, $2=$ 26 to $50 \%$ diseased, $3=51$ to $75 \%$ diseased, $4=76$ to $99 \%$ diseased, and $5=$ $100 \%$ diseased. Leaf blight symptoms were observed to be caused by infection with both $A$. dauci and $C$. carotae and were not separated based on causal organism. At harvest on 30 October 2002, 21 October 2003, and 27 October 2004, a yield sample was removed from $2.32 \mathrm{~m}$ of row and the carrot roots (all 3 years) and foliage (2002 and 2003 only) were weighed. Carrot roots were separated into three size and quality grades: jumbo carrot, $>4.4 \mathrm{~cm}$ in diameter; cello pack carrot, 2.0 to $4.4 \mathrm{~cm}$ in diameter; and culls, including misshapen roots, diseased roots, and carrot roots $<2.0 \mathrm{~cm}$ in diameter.

Air temperature and relative humidity measurements were recorded throughout the growing season from $10 \mathrm{~cm}$ above soil level in the carrot canopy using Hobo Pro Series dataloggers in 2003 and 2004 (Onset Computer Co., Bourne, MA). The data loggers recorded temperature and relative humidity every $2 \mathrm{~h}$. A single datalogger was placed in one replicate of each of the three foliar trimming treatments receiving fungicide sprays. Weather conditions at the University of Guelph-Muck Crops Research Station are summarized in Table 1. Irrigation was applied when rainfall was insufficient to maintain soil moisture above $35 \%$.

Storage samples consisting of $23 \mathrm{~kg}$ of marketable carrot were collected on the same day as the harvest assessment and placed into plastic containers in a Filacell storage maintained at a temperature of $1 \pm$ $1{ }^{\circ} \mathrm{C}$ and a relative humidity of $95 \pm 2 \%$. After 6 months, carrot roots were assessed for percent loss due to Sclerotinia rot.

The data were assessed for normality using the Shapiro-Wilk test of residuals. Outliers were identified using Lund's test of standardized residuals (18). Analysis of variance was performed on the data over the 3 years. If no interactions were found between trim number and fungicide treatment, main effects were subjected to means separation. Orthogonal contrast analysis was used to compare no-fungicide and fungicide treatments and untrimmed and trimmed treatments. Data were analyzed using the General Analysis of Variance function of the Linear Models section of Statistix V.7 and the PROC GLM, PROC PLOT, and PROC Univariate functions of SAS V.8.0 (SAS Institute, Cary, NC). A type I error rate of 0.05 was used for all statistical tests.

\section{RESULTS}

There were no treatment-year interactions for the number of apothecia that developed and data were pooled among years. Over the whole season, trimming reduced the number of apothecia compared with untrimmed treatments, but there were no significant differences between the single- and double-trimmed treatments (Table 2). The number of apothecia between first observation of apothecia and 100 DAS was lower in the trimmed treatment than in the untrimmed treatments (Table 2). At this point in the season, there were two untrimmed treatments because the once-trimmed plot had not been trimmed yet. Between 100 DAS and harvest, both trimming treatments reduced the number of apothecia compared with the untrimmed treatment. There were no differences between the two trimming treatments. Fungicide application had no effect on the number of apothecia in any period of the season.

Foliar weight was lower in the doubletrimmed treatment compared with the single-trimmed and untrimmed treatments when fungicides were applied (Table 2).

Table 1. Monthly mean temperature and rainfall at the University of Guelph-Muck Crops Research Station, Holland/Bradford Marsh, Ontario, Canada from 2002 to 2004 compared with 10 -year means

\begin{tabular}{|c|c|c|c|c|c|c|c|c|}
\hline \multirow[b]{2}{*}{ Month } & \multicolumn{4}{|c|}{ Mean temperature $\left({ }^{\circ} \mathbf{C}\right)$} & \multicolumn{4}{|c|}{ Rainfall (mm) } \\
\hline & 2002 & 2003 & 2004 & 10-year mean & 2002 & 2003 & 2004 & 10-year mean \\
\hline May & 9.9 & 12.2 & 12.4 & 12.3 & 113 & 105 & 108 & 89 \\
\hline June & 18.2 & 17.3 & 16.3 & 18.0 & 106 & 75 & 50 & 87 \\
\hline July & 21.7 & 19.9 & 19.3 & 19.9 & 76 & 29 & 102 & 73 \\
\hline August & 19.6 & 20.4 & 17.8 & 19.2 & 18 & 81 & 103 & 62 \\
\hline September & 17.5 & 15.0 & 16.6 & 15.4 & 40 & 110 & 25 & 77 \\
\hline October & 7.2 & 8.0 & 9.1 & 8.9 & 49 & 78 & 26 & 65 \\
\hline
\end{tabular}


Fungicide application resulted in higher foliar weights than in untreated carrot. Fungicide application also increased total yield compared with untreated carrot, but trimming had no significant effect on total or marketable yield. There were no treatment-year interactions for yield and yield data were pooled among years.

In all plots, fungicide application reduced CLB severity compared with no fungicide sprays (Table 3). Carrot leaf blight was lower in trimmed treatments compared with untrimmed treatments in 2003 , but there was no effect of trimming on the severity of CLB in the other 2 years and there was no fungicide-trimming interaction.

Foliar trimming reduced the mean daily relative humidity in the carrot canopy in both years. In 2003, relative humidity in the canopy for the single-trimmed treatment was reduced for approximately 2 weeks following trimming compared with the untrimmed treatment (Fig. 1). Canopy reclosure, which was used to determine the timing of the second trimming in the double-trimmed treatment, occurred at 100 DAS (Julian day 241) and, consequently, the second trimming occurred at the same date as the trimming in the single-trimmed treatment. Relative humidity was reduced for 2 weeks after this second trim. In addition, the first trimming, which was timed based on the first appearance of apothecia, resulted in lower relative humidity for the period from 7 August (Julian day 219) until the second trim on 29 August (Julian day 241) compared with the other two treatments (Fig. 1). Beyond midSeptember (Julian day 256), relative humidity was remarkably similar among treatments, except for slightly higher relative humidity in the single-trim treatment from Julian day 270 to 286 , which is unexplained. In 2004, the datalogger mal- functioned in the single-trimmed treatment. In the double-trimmed treatment, relative humidity was lower for a month following the first foliar trim at the end of July and for a month following the second foliar trim in mid-September compared with the untrimmed control (data not shown). For the 3 weeks preceding the second foliar trim, there was no difference in canopy relative humidity between the double-trimmed treatment and the untrimmed control.

Daily maximum air temperatures in the carrot canopy were higher in the trimmed treatments than in the untrimmed control for the entire period from the first foliar trimming treatment until harvest in 2003 (Table 4). In 2004, although the datalogger malfunctioned in the single-trimmed treatment, mean daily maximum air tem- peratures in the canopy were higher in the double-trimmed treatment compared with the untrimmed control from the first foliar trim on 29 July until harvest. Mean daily minimum air temperatures were not affected by foliar trimming in any period; however, in both 2003 and 2004, minimum temperatures tended to be lower in trimmed treatments during the final period before harvest (Table 4).

No disease developed in storage in any of the 3 years, and data are not reported.

\section{DISCUSSION}

Trimming of the carrot canopy reduced the number of apothecia of S. sclerotiorum in all 3 years of the trial. Trimming the canopy upon first observation of apothecia resulted in a lower number of apothecia compared with untrimmed treatments. In

Table 3. Mean leaf blight ratings over the season of carrot plants trimmed zero, one, or two times and treated with or without fungicides, 2002 to 2004

\begin{tabular}{llll}
\hline & \multicolumn{3}{c}{ Mean leaf blight rating $^{\mathbf{x}}$} \\
\cline { 2 - 4 } Trimming treatment & $\mathbf{2 0 0 2}$ & $\mathbf{2 0 0 3}$ & $\mathbf{2 0 0 4}$ \\
\hline No fungicide & & & \\
$\quad$ No trims & $3.1 \mathrm{a}$ & $2.4 \mathrm{a}$ & $3.1 \mathrm{a}$ \\
Single trim & $3.4 \mathrm{a}$ & $1.8 \mathrm{bc}$ & $3.1 \mathrm{a}$ \\
Double trim & & $2.0 \mathrm{~b}$ & $3.0 \mathrm{a}$ \\
Fungicide & $3.3 \mathrm{a}$ & & \\
$\quad$ No trims & & $1.5 \mathrm{c}$ & $1.9 \mathrm{~b}$ \\
Single trim & $2.4 \mathrm{~b}$ & $1.5 \mathrm{c}$ & $2.0 \mathrm{~b}$ \\
Double trim & $3.0 \mathrm{a}$ & $1.7 \mathrm{bc}$ & $2.1 \mathrm{~b}$ \\
Contrasts & $2.5 \mathrm{~b}$ & & $2.5 \mathrm{a}$ \\
$\quad$ Untrimmed & & $2.0 \mathrm{a}$ & $2.6 \mathrm{a}$ \\
$\quad$ Trimmed & $2.8 \mathrm{a}$ & $1.8 \mathrm{~b}$ & $3.1 \mathrm{a}$ \\
No fungicide & $3.1 \mathrm{a}$ & $2.1 \mathrm{a}$ & $2.0 \mathrm{~b}$ \\
Fungicide & $3.3 \mathrm{a}$ & $1.6 \mathrm{~b}$ & $\mathrm{ab}$ \\
\hline
\end{tabular}

${ }^{\mathrm{x}}$ Mean of leaf blight ratings over the season, rated on a scale of 0 to 5 , where $0=$ no leaf area diseased, $1=<25 \%$ diseased, $2=26$ to $50 \%$ diseased, $3=51$ to $75 \%$ diseased, $4=76$ to $99 \%$ diseased, and $5=100 \%$ diseased. Numbers in a column followed by the same letter are not significantly different at $P=0.05$, Fisher's protected least significant difference test.

y A single trim of the canopy was conducted 100 days after seeding.

${ }^{z}$ Two trims were conducted during the season, one at first observation of apothecia and the second at the time of reclosure of the canopy.

Table 2. Total month and season-long numbers of Sclerotinia sclerotiorum apothecia per $5 \mathrm{~m}$ of row following zero, one, or two foliar trimming treatments with or without fungicide application ${ }^{\mathrm{u}}$

\begin{tabular}{|c|c|c|c|c|c|c|}
\hline \multirow[b]{2}{*}{ Treatment } & \multicolumn{3}{|c|}{ Number of apothecia } & \multirow[b]{2}{*}{ Foliar weight $\left(\mathrm{kg} \mathrm{m}^{-1}\right)$} & \multicolumn{2}{|c|}{ Yield $\left(t h^{-1}\right)$} \\
\hline & First to $100 \mathrm{DAS}^{\mathrm{v}}$ & 100 DAS to harvest ${ }^{w}$ & Total & & Total & Marketable \\
\hline \multicolumn{7}{|l|}{ No fungicide } \\
\hline No trims & $4.9 \mathrm{a}-\mathrm{c}$ & $7.1 \mathrm{a}$ & $12.0 \mathrm{ab}$ & $13.6 \mathrm{bc}$ & $89.5 \mathrm{c}$ & $79.8 \mathrm{a}$ \\
\hline Single trim $^{\mathrm{x}}$ & $6.8 \mathrm{a}$ & $1.3 \mathrm{~b}$ & $8.1 \mathrm{bc}$ & $13.8 \mathrm{bc}$ & $90.5 \mathrm{bc}$ & $81.0 \mathrm{a}$ \\
\hline Double trim ${ }^{\mathrm{y}}$ & $1.2 \mathrm{bc}$ & $2.3 \mathrm{~b}$ & $3.5 \mathrm{c}$ & $12.7 \mathrm{c}$ & 89.9 bc & $81.2 \mathrm{a}$ \\
\hline \multicolumn{7}{|l|}{ Fungicide } \\
\hline No trims & $9.3 \mathrm{a}$ & $7.8 \mathrm{a}$ & $17.2 \mathrm{a}$ & $20.3 \mathrm{a}$ & $97.7 \mathrm{a}$ & $84.1 \mathrm{a}$ \\
\hline Single trim & $3.7 \mathrm{a}-\mathrm{c}$ & $0.3 \mathrm{~b}$ & $4.0 \mathrm{c}$ & $18.6 \mathrm{a}$ & $95.5 \mathrm{ab}$ & $84.7 \mathrm{a}$ \\
\hline Double trim & $0.5 \mathrm{c}$ & $1.1 \mathrm{~b}$ & $1.6 \mathrm{c}$ & $15.5 \mathrm{~b}$ & $92.6 \mathrm{a}-\mathrm{c}$ & $83.2 \mathrm{a}$ \\
\hline \multicolumn{7}{|l|}{ Contrasts } \\
\hline Untrimmed ${ }^{\mathrm{z}}$ & $6.2 \mathrm{a}$ & $7.5 \mathrm{a}$ & $14.6 \mathrm{a}$ & $17.0 \mathrm{a}$ & $93.6 \mathrm{a}$ & $82.0 \mathrm{a}$ \\
\hline Trimmed & $0.9 \mathrm{~b}$ & $1.3 \mathrm{~b}$ & $4.3 \mathrm{~b}$ & $15.2 \mathrm{a}$ & $92.1 \mathrm{a}$ & $82.5 \mathrm{a}$ \\
\hline No fungicide & $4.3 \mathrm{a}$ & $3.6 \mathrm{a}$ & $7.9 \mathrm{a}$ & $13.4 \mathrm{a}$ & $90.0 \mathrm{a}$ & $80.7 \mathrm{a}$ \\
\hline Fungicide & $4.5 \mathrm{a}$ & $3.1 \mathrm{a}$ & $7.6 \mathrm{a}$ & $18.1 \mathrm{~b}$ & $95.3 \mathrm{~b}$ & $84.0 \mathrm{a}$ \\
\hline
\end{tabular}

" Numbers in a column followed by the same letter are not significantly different at $P=0.05$, Fisher's protected least significant difference test.

${ }^{\vee}$ Between first apothecia and 100 days after seeding (DAS).

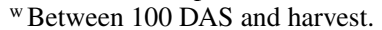

${ }^{x}$ A single trim of the canopy was conducted 100 DAS.

${ }^{y}$ Two trims were conducted during the season, one at first observation of apothecia and the second when the canopy reclosed.

${ }^{z}$ Prior to 100 DAS, only the apothecia-based trimming treatment had been performed and the 100-DAS trimming treatment was included as untrimmed. After 100 DAS, both trimming treatments were included as trimmed. 
addition, trimming the canopy 100 DAS reduced the number of apothecia compared with the untrimmed control. Because the canopy reclosed and the microclimatic effects of trimming declined within 3 or 4 weeks of trimming, both timings of trimming could be beneficial in reducing apothecia numbers. Although there were no significant differences between the singleand double-trimming treatments over the season, the lack of differences can be explained by low apothecia development late in the season as a result of dry conditions in September and October in 2 of the 3 years. Based on apothecial number alone, trimming the canopy twice during the season appears to be beneficial for the management of Sclerotinia rot in the field. Previous research demonstrated that a single foliar trimming could reduce apothecia counts (16); however, this is the first study to demonstrate that both early and late trimmings can reduce apothecial numbers.

The weight of foliage at harvest was reduced by trimming and a lack of fungicide application. However, total and marketable yields were unaffected by trimming the canopy once or twice during the season. This is consistent with the results of Kora et al. (16), where there was no reduction of yield with a single trimming. Although there was no significant effect of trimming on total yield, the carrot plants trimmed twice had the numerically lowest yields when fungicides were applied. This data suggests that trimming twice may have a small effect on total yield. Larger-scale trials would be required to accurately test yield effects of foliar trimming. It is probable that the risk of yield loss would increase as the number of foliar trims increases, but the risk of Sclerotinia rot would decrease. Thus, the potential for yield loss due to foliar trimming should be balanced with the potential reduction in losses due to Sclerotinia rot in storage. Trimming twice may be cost effective only if the risk of Sclerotinia rot is high. The number of apothecia and the number of ascospores are correlated (9) and the number of ascospores are a good indication of the potential for disease development $(9,14)$; therefore, it is likely that foliar trimming either once or twice during the season would have reduced the risk of carrot infection by S. sclerotiorum had the conditions been conducive for root infection. In the 3 years of this trial, there was no Sclerotinia rot after 6 months of cold storage. Even though Sclerotinia rot in storage is a direct consequence of infection in the field, sometimes the storage phase does not develop despite field infection (13).

The effect of foliar trimming on apothecial development can be attributed mostly to a reduction in relative humidity in the canopy and, presumably, the reduction in soil moisture and leaf wetness that results.
This is confirmed by the work of Kora et al. (16), who showed that a single foliar trimming treatment reduces relative humidity in the canopy during the daylight hours. The effects of foliar trimming on the canopy microclimate appear to last between 2 and 4 weeks after the treatment. Consequently, the benefit of foliar trimming twice during the season is a longer time period in which there is a less favorable environment for apothecial development. Daily maximum air temperatures in the canopy increased with increasing number of foliar trimmings. The data suggest that infection and development of Sclerotinia rot within the canopy, even in areas protected by leaf cover, could be reduced as a result of air temperatures increasing above the preferred range of $S$. sclerotiorum in trimming treatments. Optimal temperatures are between 10 and $20^{\circ} \mathrm{C}$ for apothecial expansion $(1,11)$ and between 15 and $18^{\circ} \mathrm{C}$ for infection (23). Although mean daily maximum air temperatures were above these ranges for all treatments during August and early September, the lower maximums in the untrimmed treatment suggests that temperatures would have been in the optimum range for a longer period of time in this treatment.

In 2 of the 3 years, there was no effect of foliar trimming on CLB severity. In 2003 , trimming resulted in a small reduction in leaf blight severity compared with untrimmed treatments. Disease severity was lower in 2003 compared with other years. Thus, it is possible that trimming, and the corresponding change in relative humidity and leaf wetness, may have more effect on CLB when environmental conditions are not very favorable for disease development (i.e., leaf wetness period $<12$ $\mathrm{h}$ in duration; 12,17) and, consequently, disease pressure is low. Overall, there is little evidence to support the hypothesis that foliar trimming improves fungicide

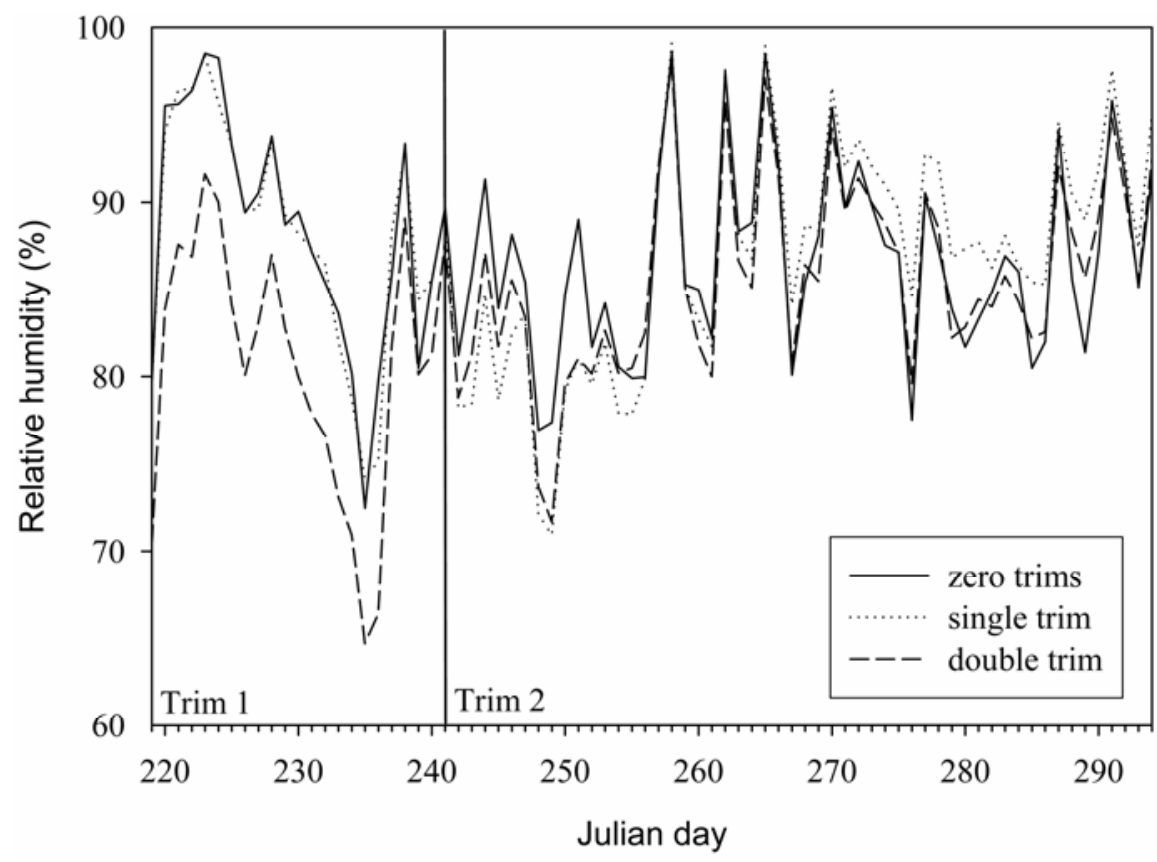

Fig. 1. Mean daily relative humidity in the carrot canopy as affected by foliar trimming treatments in 2003. The foliar trimming treatments occurred on Julian day 241 (29 August) for the trimming 100 days after seeding (single trim) and Julian days 219 and 241 (7 and 29 August) for the apothecia-based trimming treatment (double trim).

Table 4. Mean daily maximum and minimum air temperatures in the canopy in three periods during the growing season for carrot given zero, one, or two foliar trimming treatments ${ }^{\mathrm{z}}$

\begin{tabular}{|c|c|c|c|c|c|c|}
\hline \multirow[b]{2}{*}{ Treatment } & \multicolumn{3}{|c|}{ Mean daily maximum $\left({ }^{\circ} \mathrm{C}\right)$} & \multicolumn{3}{|c|}{ Mean daily minimum $\left({ }^{\circ} \mathrm{C}\right)$} \\
\hline & Period 1 & Period 2 & Period 3 & Period 1 & Period 2 & Period 3 \\
\hline \multicolumn{7}{|l|}{2003} \\
\hline No trim & $26.7 \pm 0.42$ & $26.6 \pm 0.82$ & $18.0 \pm 0.97$ & $13.1 \pm 0.98$ & $8.6 \pm 0.99$ & $3.2 \pm 0.71$ \\
\hline Single trim & $29.0 \pm 0.51$ & $28.9 \pm 0.82$ & $19.2 \pm 1.00$ & $13.1 \pm 0.99$ & $8.5 \pm 1.02$ & $3.0 \pm 0.73$ \\
\hline Double trim & $31.1 \pm 0.71$ & $28.1 \pm 0.75$ & $19.3 \pm 1.02$ & $13.0 \pm 0.97$ & $8.6 \pm 0.98$ & $3.0 \pm 0.71$ \\
\hline \multicolumn{7}{|l|}{2004} \\
\hline No trim & $24.0 \pm 0.58$ & $23.1 \pm 0.54$ & $16.8 \pm 0.87$ & $10.6 \pm 0.83$ & $12.7 \pm 0.83$ & $3.9 \pm 0.67$ \\
\hline Double trim & $25.3 \pm 0.57$ & $23.9 \pm 0.57$ & $20.0 \pm 1.29$ & $10.9 \pm 0.82$ & $12.6 \pm 0.86$ & $3.3 \pm 0.70$ \\
\hline
\end{tabular}

${ }^{\mathrm{z}}$ Period 1 (the period between the first development of apothecia and 100 days after seeding [DAS] =

7 to 28 August 2003 and 29 July to 26 August 2004; Period 2 (the time 100 DAS and the end of the effect of trimming on canopy relative humidity) $=29$ August to 13 September 2003 and 27 August to 16 September 2004; Period 3 (the period between Period 2 and harvest) $=14$ September to 20 October 2003 and 17 September to 26 October 2004. Data reported as mean \pm standard error. 
penetration into the canopy. Furthermore, the modification of the canopy microclimate appears to have little effect on CLB severity. CLB severity is much less dependent on canopy microclimate because sporulation and infection can occur during the overnight period and are not as dependent on extended periods of leaf wetness or high relative humidity as $S$. sclerotiorum $(5,6,12,17)$. The trimming could be more effective in reducing disease severity when the canopy is denser.

Trimming the carrot foliage once effectively reduces the number of apothecia of $S$. sclerotiorum and trimming twice may even be more effective in reducing apothecia and, hence, disease development. This is due to a reduction in relative humidity within the canopy following trimming and a less favorable environment for apothecial development. Trimming does not reduce CLB severity or improve the efficacy of fungicide applications. Foliar trimming needs to be evaluated in larger-scaled field trials to confirm that there is no reduction in yield.

\section{ACKNOWLEDGMENTS}

Funding for this project was provided by the Agricultural Adaptation Council through the support of the Ontario Fruit and Vegetable Grower's Association and by the Ontario Ministry of Agriculture, Food and Rural Affairs/University of Guelph Plant Program. We thank M. Hovius and the staff of the Muck Crops Research Station for their technical assistance and C. Kora for her input in the initial stages of this research.

\section{LITERATURE CITED}

1. Abawi, G. S., and Grogan, R. G. 1975. Source of primary inoculum and effects of temperature and moisture on infection of bean by Whetzelinia sclerotiorum. Phytopathology 65:300-309.
2. Abawi, G. S., and Grogan, R. G. 1979. Epidemiology of diseases caused by Sclerotinia species. Phytopathology 69:899-904.

3. Abraham, V., Kushalappa, A. C., Carisse, O., Bourgeois, G., and Auclair, P. 1995. Comparison of decision methods to initiate fungicide applications against Cercospora blight of carrot. Phytoprotection 76:91-99.

4. Caesar, A. J., and Pearson, R. C. 1983. Environmental factors affecting survival of ascospores of Sclerotinia sclerotiorum. Phytopathology 73:1024-1030.

5. Carisse, O., and Kushalappa, A. C. 1990. Development of an infection model for Cercospora carotae on carrot based on temperature and leaf wetness duration. Phytopathology 80:1233-1238.

6. Carisse, O., and Kushalappa, A. C. 1992. Influence of interrupted wet periods, relative humidity, and temperature on infection of carrots by Cercospora carotae. Phytopathology 82:602-606.

7. Finlayson, J. E., Pritchard, M. K., and Rimmer, S. R. 1989. Electrolyte leakage and storage decay of five carrot cultivars in response to infection by Sclerotinia sclerotiorum. Can. J. Plant Pathol. 11:313-316.

8. Finlayson, J. E., Rimmer, S. R., and Pritchard, M. K. 1989. Infection of carrots by Sclerotinia sclerotiorum. Can. J. Plant Pathol. 11:242-246.

9. Foster, A. 2006. Forecasting Sclerotinia rot of carrot. M.Sc. thesis, Department of Plant Agriculture, University of Guelph, Guelph, Ontario, Canada.

10. Geary, J. R. 1978. Host-parasite interactions between the cultivated carrot (Daucus carota) and Sclerotinia sclerotiorum (Lib.) de Bary. $\mathrm{Ph} . \mathrm{D}$. thesis, University of East Anglia, East Anglia, UK.

11. Hao, J. J., Subbarao, J. V., and Duniway, J. M. 2003. Germination of Sclerotinia minor and $S$. sclerotiorum sclerotia under various soil moisture and temperature combinations. Phytopathology 93:443-450.

12. Hooker, W. J. 1944. Comparative studies of two carrot leaf diseases. Phytopathology 34:606-612.

13. Kora, C. 2003. Etiology, epidemiology, and management of Sclerotinia rot of carrot caused by Sclerotinia sclerotiorum (Lib.) de Bary. Ph.D. thesis, University of Guelph, Guelph, Ontario, Canada.

14. Kora, C., McDonald, M. R., and Boland, G. J. 2003. Sclerotinia rot of carrot: an example of phonological adaptation and bicyclic development of Sclerotinia sclerotiorum. Plant Dis. 87:456-470.

15. Kora, C., McDonald, M. R., and Boland, G. J. 2005a. Epidemiology of Sclerotinia rot of carrot caused by Sclerotinia sclerotiorum. Can. J. Plant Pathol. 27:247-358.

16. Kora, C., McDonald, M. R., and Boland, G. J. 2005b. Lateral trimming of canopy influences the microclimate and development of apothecia of Sclerotinia sclerotiorum in carrots. Plant Dis. 89:549-557.

17. Langenberg, W. J., Sutton, J. C., and Gillespie, T. J. 1977. Relation of weather variables and periodicities of airborne spores of Alternaria dauci. Phytopathology 67:879-883.

18. Lund, R. E. 1975. Tables for an approximate test for outliers in linear models. Technometrics 17:473-476.

19. Neergaard, P. 1945. Danish species of Alternaria and Stemphylium. Oxford University Press, London.

20. Ontario Ministry of Agriculture, Food, and Rural Affairs. 2006. Vegetable production recommendations 2006-2007. Publication 363. Queen's Printer for Ontario, Toronto.

21. Pryor, B. M., and Strandberg, J. O. 2001. Alternaria leaf blight of carrot. In: Compendium of Umbelliferous Crop Diseases. R Davis and R. N. Raid, eds. The American Phytopathological Society Press, St. Paul, MN.

22. Pryor, B. M., Strandberg, J. O., Davis, R. M., Nunez, J. J., and Gilbertson, R. L. 2002. Survival and persistence of Alternaria dauci in carrot cropping systems. Plant Dis. 86:11151122.

23. Rubatzky, V. E., Quiros, C. F., and Simon, P. W. 1999. Carrots and Related Vegetable Umbelliferae. CABI Publishing, New York.

24. Sutton, J., and Gillespie, T. 1979. Weathertimed sprays for carrot blight control. Ontario Ministry of Agriculture, Food, and Rural Affairs. FactSheet 79-035. 